\title{
Coalition theories: empirical evidence for dutch municipalities
}

\author{
BERNARD STEUNENBERG \\ Faculty of Public Administration and Public Policy, Department of Economics, \\ University of Twente, The Netherlands
}

\begin{abstract}
The paper analyzes coalition formation in Dutch municipalities. After discussing the main features of the institutional setting, several theories are discussed, which are classified as size oriented, policy oriented and actor oriented models. A test statistic is proposed to determine the predictive power of these models. The empirical analysis shows that strategic positions as well as some of the distinguished preferences are important in the setting of Dutch municipalities. Especially, the dominant minimum number principle yields highly significant results for coalition formations in the period 1978-1986.
\end{abstract}

\section{Introduction}

Most empirical studies on coalition theories use data on cabinet formation for central governments. Well-known examples are the studies of Browne (1970), De Swaan (1973) and Taylor and Laver (1973). Recently empirical evidence for this level of government was reported in Peleg (1981), Browne and Dreijmanis (1982), Browne, Gleiber and Mashoba (1984) and Schofield (1987). Less attention is paid to the formation of coalitions in local governments. In Mellors and Pijnenburg (1989) qualitative analyses are found for coalition formation in local government in various European countries. Laver, Rallings and Thrasher (1987) provided some insights for local government in Britain. Boute (1988) tested several hypotheses for Belgian municipalities and found highly significant predictions for the set of size oriented models. Denters (1985: 305) conducted a test for larger Dutch municipalities; he did not find any significant results at all, but this might be due to an inappropriate test statistic that was used. ${ }^{1}$ Further, Denters tested only a few hypotheses for a relatively small number of municipalities. In this paper, tests of the predictive power of size oriented models, policy oriented models and actor oriented models of local government formation are reported for a larger number of municipalities and for several points in time.

With regard to coalition formations in Dutch municipalities, several questions can be raised. Are size oriented models more appropriate, as in the Belgian case, or do we find better results for policy oriented models, as Franklin and Mackie (1984: 686) found for Dutch cabinet formations? Is it true that coalition theories are not able to explain coalition formation in Dutch 
local government, as Denters concluded, or does it turn out that certain theories can explain this phenomenon when an appropriate test statistic is used? To what extent can the more recently suggested models predict the outcomes of formation processes? Beside these questions the most important one is, of course: Which insights can be provided by a test of coalition theories at the local level?

Before turning to the setting of Dutch local government, a distinction has to be made with respect to the rules used in the formation process, which are neglected in previous studies. If all players are allowed to propose some coalition at the same time, a formation process is called unrestricted. This implies that no one can be excluded from the agenda, and that no rule governs the sequence of alternatives presented to the other players. A formation process is called restricted if only one player is allowed to choose some action, such as to propose a coalition.

Formation processes also differ with respect to the extent to which players are able to affect the outcome. Cabinet formations in The Netherlands are governed by several informal rules. First, the Queen appoints one of the party leaders to investigate 'the possibilities of forming a coalition' after consulting all political parties represented in the new parliament. Second, the leaders of the parties in parliament 'negotiate' their inclusion in a majority coalition under 'the more or less active leadership of the formateur' (De Swaan, 1982: 221). Third, the formateur, as a member of one of the main parties, can freely operate without being accountable to parliament. In his study of cabinet formations in the period 1959-1973 Maas (1982: 375) observes that the formateur'. . actually decides on vital national issues such as basis, programme and composition of a future cabinet. Also, his personal views and wishes can play a role, without parliament being able to do much about it' (translated from Dutch). Thus, the formateur arrangement provides one of the political parties in particular with the opportunity to influence coalition formation. Moreover, this arrangement also suggests that the coalition formation process at the national level in the Netherlands can be characterized as restricted.

At the local level there is a different arrangement, which has its roots in the local political system. ${ }^{2}$ Formally, the sovereign body of a Dutch municipality is the municipal council. Its members are elected in general elections for periods of four years. Municipal policies are prepared and proposed by an executive committee, which is called the Council of Mayor and Aldermen. The Mayor is appointed by the central government for a period of six years. ${ }^{3}$ All Aldermen are elected by the municipal council from among its members using simple majority rule.

After the elections all political parties in the municipal council start negotiations to determine the political composition of the Council of Mayor and Aldermen. Contrary to formation processes at the national level, no formateur 
is appointed and parties directly bargain among each other to be represented in the executive body. Under this arrangement any party may propose some 'coalition' of the members of the municipal council to be appointed as Aldermen, and none of these proposals is excluded from the 'formal' agenda. Of course, depending on some behavioural model, political parties may prefer to form a coalition with specific players. Thus, contrary to cabinet formations, the formation of a Council of Mayor and Aldermen in the Netherlands can be typified as an unrestricted process.

Different institutional arrangements may affect the outcome of formation processes. Outcomes of restricted processes can be influenced by the player with a mandate to form a government. Recall, for instance, Maas' observation for cabinet formations in the Netherlands. At the local level this mechanism is absent, and strategies of all players will be much more important. However, giving attention to institutional arrangements does not imply that the preferences of participants can be neglected. Institutional arrangements only determine the context in which a player makes his or her choice. This choice itself has to be based on some behavioural model. Thus, the motivations stressed by policy and size or office-oriented models might also be needed to explain coalition formation.

Given this, we need to ask whether office or policy considerations are expected to be dominant in the context of Dutch local government. In the Netherlands, the policies of local governments are mainly determined by the central government. Municipalities, for example, have to cope with centrally enforced regulation and receive most of their revenues from the central government. Furthermore, the central government uses municipalities to carry out most of its policies. Beside giving local government limited ability to develop and implement local policies, the importance of the central government also results in an orientation of voters towards primarily national policy issues instead of local ones (see Denters, 1985: 296; Kuiper \& Tops, 1989: 227). One of the consequences of this is that local politicians are rarely held responsible for their policies. Policy considerations, therefore, may play a minor role in local coalition formation in the Netherlands: office considerations will be much more important. Thus, in the context of local government in the Netherlands, preferences presumed by office-oriented models are expected to explain coalition formation better than preferences presumed by policy oriented models.

The outline of the paper is as follows: Section 2 discusses the so-called size, policy and actor oriented models. In this section, hypotheses are derived about coalition formation. In Section 3 additional assumptions are introduced in order to test these hypotheses in the context of Dutch local government. Attention is paid to local lists and the ordering of parties on a policy scale. In Section 4 statistical tests for the predictive power of coalition theories are 
discussed. The results of the empirical analysis are reported in Section 5. Section 6 concludes the paper.

\section{Theories}

Models of coalition formation can be distinguished into (1) size or office oriented models, (2) policy oriented models, and (3) actor oriented models. Size and policy oriented models presume some behavioural model of bargaining between players to derive hypotheses about coalition formation. On the other hand, actor oriented models focus on the position of some particular player in a bargaining process.

To discuss the various models, some simple notation is needed. Let $N=\{1$, $2,3, \ldots n$ be a set of $n$ players in a voting body. A coalition $S$ is any subset of $N$. Define $W$ as the set of winning coalitions. Coalitions not in $\mathrm{W}$ are called losing coalitions. If votes are unequally distributed among the players, a weight can be assigned to each player $i, i \in N$, which represents the number of available votes, denoted as $w(i)$. The number of votes controlled by a coalition $S$, or its weight, is defined as: $w(S)=\sum w(i), S \subseteq N$ with $w(i)$ summed over all $i$, $i \in S$. The minimum number of votes that is sufficient to adopt a proposal is called a quotum, denoted as $q$. Now, a coalition $S$ is an element of the set of winning coalitions $W$ if $w(S) \geqslant q$. Further, a coalition $T$ is an element of the set of losing coalitions $L$ if this condition is not satisfied. In other words: $T \in L$ if $w(T)<\mathrm{q}$. For coalition formations in the Dutch local political system simple majority rule is used. So, in this paper, $q$ is defined as:

$$
\left(\sum \mathrm{w}(\mathrm{i})+1\right) / 2 \leqslant \mathrm{q} \leqslant \sum \mathrm{w}(\mathrm{i}) / 2+1,
$$

where $q$ is an element of the set of integers and $w(i)$ is summed over all $i \in N$. Furthermore, in the context of Dutch municipalities players are to be considered as political parties. The seats of these parties in the municipal council determine their weights.

\subsection{Size oriented models}

Size oriented models assume that political parties are exclusively interested in the benefits of being in office, which are often conceived as membership of government, cabinet portfolios or variables related with the control of departments. To be sure of the highest possible 'payoff', coalitions should be as small as possible. In contrast to policy oriented models these models do not take into 
account policy considerations, which may be important for the re-election of political parties. The size oriented models are distinguished into minimum number winning principle, minimum size principle and minimum number principle. The latter two can be regarded as extensions of the first principle.

Minimum winning principle (Von Neumann \& Morgenstern, 1974 [1944]). The set of minimum winning coalitions, denoted by $W^{m}$, is defined as follows:

$$
W^{m}=\{S \in W \mid \text { for all } i \in S, S-\{i\} \in L\}
$$

If, however, $S-\{i\} \in W$, then a party $i$ is called an unneccessary actor in coalition $S$. Assuming that (1) coalition formation is of a constant sum, in other words the net-benefits for all winning coalitions are constant, and (2) the benefits for each winning coalition are independent of the number of members, it can be deduced that political parties will form winning coalitions that do not contain unnecessary actors.

Hypothesis I: In a formation process, only coalitions from $W^{m}$ will be formed. ${ }^{4}$

Minimum size principle (Gamson, 1961; Riker, 1962). ${ }^{5}$ The set of minimum size coalitions, denoted by $W^{s}$, is defined as:

$$
W^{s}=\{S \in W \mid \text { for all } T \in W, T \neq S, w(S) \leqslant w(T)\}
$$

Concerning the distribution of 'payoffs' it is assumed that the members of a winning coalition divide the benefits of forming such a coalition proportionally to their weights (see Gamson, 1961: 376). So, political parties try to form coalitions without unnecessary actors that also have the smallest weight.

HyPOTHESIS 2: In a formation process, only coalitions from $W^{s}$ will be formed.

Minimum number principle (Leiserson, 1968). The set of minimum number coalitions, denoted by $W^{n}$, is defined as follows:

$$
W^{n}=\{\mathrm{S} \in \mathrm{W} \mid \text { for all } \mathrm{T} \in \mathrm{W}, \mathrm{T} \neq \mathrm{S}, \mathrm{m}(\mathrm{S}) \leqslant \mathrm{m}(\mathrm{T})\}
$$

with $m(S)$ as the number of political parties that are member of coalition $S$. This model assumes that the costs of decision making within a coalition increase with the number of members. Given this assumption, parties strive to 
form coalitions that are minimum winning and contain the smallest number of actors. In accordance with De Swaan (1973: 65-7) the following hypothesis is proposed:

HYPOTHESIS 3: In a formation process, only coalitions from $W^{n}$ will be formed.

\subsection{Policy oriented models}

If voters determine their party choice on the extent to which a party has kept its promises in the previous government period, political parties are to be expected to give preference to coalitions which are as ideologically cohesive as possible (minimum range theory or minimum diversity theory) or as close as possible to its own policy position (policy distance theory). In that case political parties have the highest chance of achieving their own policy objectives and secure the support of their electorate. As indicated in the introduction, the behavioral presumption of this class of models is expected to be less appropriate for the context of Dutch municipalities than the one of size oriented models.

Depending on the dimensionality of the ideological space of politics the policy oriented models are distinguished into one-dimensional and multidimensional models. ${ }^{6}$ In this paper the attention is restricted to one-dimensional models because multidimensional data for local politics in the Netherlands are not available. In Section 3.3 a dominant policy dimension will be proposed assuming that local branches of national political parties are restricted in formulating their own policy objectives.

Axelrod's Conflict of Interest theory will not be tested (Axelrod, 1970). This theory 'predicts' closed minimum winning coalitions (or closed minimum range coalitions in De Swaan's terminology), which should minimize the conflict of interest among their members. However, this set of coalitions can not be deduced from Axelrod's assumptions as Taylor (1972) and, later, De Swaan (1973: 77) indicated. Thus, large numbers of connected coalitions, which are frequently found in empirical research, do not necessarily support Axelrod's hypothesis. Moreover, Browne, Gleiber and Mashoba (1984: 25), who performed an alternative test based on cardinal measures of the policy positions of political parties, concluded that Axelrod's theory is ' . . insufficient to explain the formation and duration of cabinet formations'.

Minimum range principle (Leiserson, 1966; De Swaan, 1973: 71-5). Assume that the ideological cohesiveness of a coalition is determined by its range: The smaller this range, the greater is the cohesiveness. Assume an ordinal policy 
scale for which the policy position of each political party is indicated by an ordinal number $p_{i}$. The range of a coalition can be determined by the policy position of its extreme members. De Swaan defines the range of a coalition $S$, denoted by $D(S)$, as:

$$
\mathrm{D}(\mathrm{S})=\mathrm{d}\left(\mathrm{p}_{\mathrm{L}}^{\mathrm{s}}, \mathrm{p}_{\mathrm{R}}^{\mathrm{s}}\right)
$$

with $p_{L}{ }^{s}$ as the policy position of the left most party $\left(p_{L}{ }^{s} \leqslant p_{i}\right.$, for all $\left.\mathrm{i} \in \mathrm{S}\right)$ and $p_{R}{ }^{s}$ as the policy position of the right most party of $S\left(p_{R}{ }^{s} \geqslant p_{i}\right.$, for all $\left.\mathrm{i} \in \mathrm{S}\right)$. The range of a coalition $T, T \neq S$, is larger than the range of $S$ if:

$$
\mathrm{p}_{\mathrm{L}}^{\mathrm{T}}<\mathrm{p}_{\mathrm{L}}^{\mathrm{s}} \text { and } \mathrm{p}_{\mathrm{R}}^{\mathrm{T}} \geqslant \mathrm{p}_{\mathrm{R}}^{\mathrm{s}}
$$

or

$$
\mathrm{p}_{\mathrm{L}}^{\mathrm{T}} \leqslant \mathrm{p}_{\mathrm{L}}^{\mathrm{S}} \text { and } \mathrm{p}_{\mathrm{R}}^{\mathrm{T}}>\mathrm{p}_{\mathrm{R}}^{\mathrm{S}},
$$

and is equal if

$$
\mathrm{p}_{\mathrm{L}}^{\mathrm{T}}=\mathrm{p}_{\mathrm{L}}^{\mathrm{S}} \text { and } \mathrm{p}_{\mathrm{R}}^{\mathrm{T}}=\mathrm{p}_{\mathrm{R}}^{\mathrm{S}}
$$

However, it is not always possible to determine whether the range of a coalition is greater (or smaller) than the range of another coalition. If such a comparison cannot be made, both coalitions are admitted to the prediction set. The set of minimum range coalitions, denoted by $W^{r, o}$ is defined as:

$$
W^{r, o}=\{S \in W \mid \text { for all } T \in W, T \neq S, D(S) \leqslant D(T) \text { or } D(S) \gtrless D(T)\} \text {. }
$$

If political parties prefer coalitions that are as ideologically cohesive as possible, they will strive to form a governing coalition that has the smallest range possible. Thus:

Hyportesis 4: In a formation process, only coalitions from $W^{\text {roo }}$ will be formed.

If a policy scale is interpreted as an interval scale (see De Swaan, 1973: 75), the set of minimum range coalitions can be defined as:

$$
W^{r, i}=\{S \in W \mid \text { for all } T \in W, T \neq S, \triangle(S) \leqslant \Delta(T)\}
$$

with $\triangle(S)$ as: 


$$
\triangle\left(\mathrm{p}_{\mathrm{L}}^{\mathrm{s}}, \mathrm{p}_{\mathrm{R}}^{\mathrm{s}}\right)=\left|\mathrm{p}_{\mathrm{L}}^{\mathrm{s}}-\mathrm{p}_{\mathrm{R}}^{\mathrm{s}}\right|
$$

In this case $p_{i}$ is to be considered as a cardinal number. This version of the minimum range principle leads to the following hypothesis:

HypothesIS 5: In a formation process, only coalitions from $W^{r, i}$ will be formed.

Minimum diversity principle (Leiserson, 1966; Taylor \& Laver, 1973: 217). In contrast to the minimum range principle the ideological cohesiveness of a coalition can also be determined by a diversity measure proposed by Leiserson (1966: 343-4). The ideological diversity, $I D(S)$, of a coalition $S$ is defined as the number of 'spaces' and 'holes' separating the coalition members for a specific ranking of players. For example, using the ranking $p_{i}<p_{j}<p_{k}$ for $i, j$ and $k$, the ideological diversity of coalition $\{i, j\}$ is equal to one (one space, no holes), $I D\{i, j, k\}=2$ (two spaces, no holes), and $I D\{i, k\}=3$ (two spaces, one hole). The set of minimum diversity coalitions, $W^{\text {id }}$, is defined as follows:

$$
W^{i d}=\{\mathrm{S} \in \mathrm{W} \mid \text { for all } \mathrm{T} \in \mathrm{W}, \mathrm{T} \neq \mathrm{S}, I D(\mathrm{~S}) \leqslant I D(\mathrm{~T})\} .
$$

If political parties prefer ideological cohesive coalitions, they will try to form coalitions that are the less diverse. This principle leads to the following hypothesis:

Hypothesis 6: In a formation process, only coalitions from $W^{\text {id }}$ will be formed.

Subjective policy distance principle (De Swaan, 1973; Boute, 1981, 1984). According to the policy distance theory political parties prefer a winning coalition as close as possible to their own policy positions. In its original formulation (see De Swaan, 1973: 80-104) these distances are regarded as 'objective' entities, that is, they are seen as being equal for all political parties. Boute (1981) showed that it is not always possible to determine these distances unambiguously using De Swaan's assumptions. For instance, two 'pivotal' parties can be identified within the same coalition causing such a coalition to appear twice in the preference ordering of its members. Boute (1984) has proposed a re-formulation of De Swaan's theory towards a 'subjective' version. Beside 'subjective' distances with respect to winning coalitions, each party is assumed to neglect a second identical coalition within its 'subjective' ordering. This version of the theory will be tested in this paper.

Let $U$ be the set of undominated coalitions to be determined by the assump- 
tions introduced by Boute (1984: 125-6). Then, the set of policy distance minimizing coalitions, denoted by $W^{\text {spd }}$, is defined as follows:

$$
W^{s p d}=\{S \in W \mid S \in U\} .
$$

In some cases, however, it is not clear whether coalitions are dominated or not. A political party may find coalitions to its 'left' and its 'right' for which it is not possible to compare policy 'distances' using an ordinal policy scale. This problem leads to a so-called 'forked preference ordering' (see De Swaan, 1973: 106), which may result in the impossibility to determine whether a specific coalition is dominated. The set of coalitions to which this problem applies, is called the set of undetermined coalitions, $U^{\prime}$. So, a second prediction set can be defined including these undetermined coalitions:

$$
W^{s p d, u}=\left\{\mathrm{S} \in \mathrm{W} \mid \mathrm{S} \in \mathbf{U} \text { or } \mathbf{S} \in \mathbf{U}^{\prime}\right\} .
$$

Within the scope of the subjective policy distance theory the following two hypotheses are proposed:

HyPoTHESIS 7: In a formation process, only coalitions from $W^{\text {spd }}$ will be formed.

Hypothesis 8: In a formation process, only coalitions from $W^{s p d, u}$ will be formed.

\subsection{Actor oriented models}

The third category of models tries to explain the formation of governing coalitions using certain properties of specific political parties. These properties proceed from different notions of power. For example, a party can be considered as powerful if he is a dictator within a coalition and, in addition, if he is able to form a winning coalition with oppositional parties while this is not feasible for the other coalition members ('dominant player'). Another aspect of power is involved if a party is pivotal within an ideological space ('central player'). Within this class of models powerful actors are expected to affect coalition formation.

Dominant player principle (Peleg, 1981; Van Deemen, 1989). A 'dominant' player, such as a political party, is assumed to have power to be decisive with respect to the choice of the governing coalition. Domination is defined as follows. A player $i$ weakly dominates a coalition $S, S \in W, i \in S$, if for every coalition $B, B \subseteq N-S$, the following condition holds: 
(1) if $B \cup S-\{i\} \in W$, then $B \cup\{i\} \in W$.

Thus, if the internal opposition of player $i$ can win with one or more players in $B$, then these players must also be able to win with $i$, if player $i$ is to be said to dominate coalition $S$ weakly. However, a player $i$ dominates a coalition $S, S \in$ $W, i \in S$, if, in addition to condition (1), there are coalitions $B, B \subseteq N-S$, such that the following condition holds as well:

(2) if $B \cup\{i\} \in W$, then $B \cup S-\{i\} \in L$.

If player $i$ can win with $B$, but $S-\{i\}$ cannot, then this player dominates coalition $S$. This player, who satisfies condition (1) as well as condition (2), is called a dominant player. A coalition formation process with a dominant player is called a dominated formation process.

Peleg (1981: 13) showed that the set of dominant players is at most one player in weighted majority games. ${ }^{7}$ The dominant player is able to form winning coalitions with parties that are oppositional to that coalition, while the other coalition members cannot form winning coalitions with them. Van Deemen (1989: 323) proved that the dominant player is a dictator in the coalition he dominates. So, the dominant player can be regarded as a powerful player in the formation process, especially if he is given a mandate to form a governing coalition. ${ }^{8}$ Therefore, it is expected that in dominated games only coalitions with the dominant player are formed.

Let $W^{d, w}$ be the set of weakly dominated coalitions, $W^{d}$ the set of dominated coalitions, and $i$ the dominant player. Both sets are defined as follows:

$$
W^{d, w}=\{\mathrm{S} \in \mathrm{W} \mid \text { i weakly dominates } \mathrm{S}\}
$$

and:

$$
W^{d}=\{\mathrm{S} \in \mathrm{W} \mid \text { i dominates } \mathrm{S}\} .
$$

Applying the dominant player principle to the formation of coalitions between political parties, the following hypotheses are proposed (see Peleg, 1981: 18; Van Deemen, 1989: 324).

HYPOTHESIS 9: In a dominated formation process, only coalitions from $W^{d, w}$ will be formed.

Hypothesis I0: In a dominated formation process, only coalitions from $W^{d}$ will be formed.

Weak domination is a rather limited concept of power. It is, therefore, 
expected that hypothesis 10 explains coalition formation better than hypothesis 9 . Also note that hypothesis 10 is more restrictive than hypothesis 9 because $W^{d} \subseteq W^{d, w} \subseteq \mathrm{W}$.

Central player principle (Einy 1985, 109; Van Deemen, 1990: 190-2). A player is central in a policy order, if all the other players to its left or to its right can only form a winning coalition with this player. More precisely, a player $i$ is called a central player if, given a ranking of players:

(1) $L(i, N) \cup\{i\} \in W$ and $L(i, N) \in L$, and if

(2) $R(i, N) \cup\{i\} \in W$ and $R(i, N) \in L$,

with $L(i, N)$ as the set of players to the left of $i$ 's policy position, and $R(i, N)$ as the set of players to the right of $i$. If a game is proper (the complement of a winning coalition is always losing) and strong (the complement of a losing coalition is always winning), then a central player exists, and it is proven to be only one player (Van Deemen, 1990: 191). If a central player occurs, a formation process is called a centralized process.

Because of his position the central player can assure himself of a majority, or prevent a hostile majority from forming. In this respect the central player is a powerful player, who can influence the outcome of the formation process. Consequently, in centralized games only coalitions with the central player will be formed.

An implicit assumption of this model is that players have some policy preference and, therefore, do not pass the central player on the policy scale with respect to coalition formations. Thus, the central player principle mixes a strategic consideration with policy preferences. As indicated in the introduction, such a model is expected to work better in the context of Dutch municipalities than models only emphasizing one of these features. However, policy preferences are expected to be less appropriate for the studied setting because of the primarily 'national' orientation of voters, which reduces the potential usefulness of this model.

If the political party $i$ is a central player, the following set of 'centralized' coalitions, $W^{c}$, can be defined:

$W^{c}=\{S \in W \mid i$ is central in the policy order and $i \in S\}$,

leading to the following hypothesis (see Roozendaal, 1989: 262):

HYPoTHESIS I I: In a centralized formation process, only coalitions from $W^{c}$ will be formed. 
Combinations. Several combinations of actor oriented models are suggested of which the following combinations are tested in this paper:

Dominant central player principle (Roozendaal, 1989). In some cases the dominant player is also a central player. This combination of powerful positions and the presumed policy preferences of political parties leads to the following hypothesis:

Hypothesis 12: In a formation process for which the dominant player is equal to the central player, only coalitions from $W^{d} \cap W^{c}$ will be formed.

Dominated minimum winning principle. ${ }^{9}$ The combination of the dominant player principle and the minimum winning principle holds the following hypotheses:

HyPoTHESIS 13: In a dominated formation process, only coalitions from $W^{d, w} \cap W^{m}$ will be formed.

Hypothesis 14: In a dominated formation process, only coalitions from $W^{d} \cap W^{m}$ will be formed.

Dominated minimum size principle (Van Deemen, 1989: 325-8). This combination of principles has led to the following hypotheses:

HYPOTHESIS 15: In a dominated formation process, only coalitions from $W^{d, w} \cap W^{s}$ will be formed.

HYPOTHESIS I6: In a dominated formation process, only coalitions from $W^{d} \cap W^{s}$ will be formed.

Dominated minimum number principle. The combination of the dominant player principle and the minimum number principle yields the following hypotheses:

HyPOTHESIS I7: In a dominated formation process, only coalitions from $W^{d, w} \cap W^{n}$ will be formed.

HYPOTHESIS I8: In a dominated formation process, only coalitions from $W^{d} \cap W^{n}$ will be formed.

3. Council of Mayor and Aldermen in Dutch municipalities and the intended test of the hypotheses

In Dutch municipal councils, political parties are represented on a proportion- 
al basis. As a consequence more than two political parties are represented in most councils. After the 1986 elections, for example, the average number of political parties represented was $4.8 .{ }^{10}$ Frequently no single party has a majority of the seats, so a coalition of parties has to form the Council of Mayor and Aldermen.

The political parties represented in municipal councils can be distinguished into national lists and local lists (Dittrich, 1978: 19). National lists are local branches of national political parties. They include parties such as the 'Christian Democrats' (CDA), the 'Labor Party' (PvdA) and the 'Liberal Party' (VVD), ${ }^{11}$ and specific combinations of local branches of national parties. An example of the latter is the 'Progressive Alliance' (PAK), which consists of varying combinations of PvdA, D'66, PPR, PSP and CPN. Local lists do not have a national counterpart and they are typically bound to a specific municipality. These lists embody various political groupings with different policy preferences. ${ }^{12}$

The Council of Mayor and Aldermen, as the municipal executive committee, dominates the municipal council with regard to decision making (Denters and Kerver, 1981: 346-347). This implies that, if a political party is not represented in this body, it misses an important basis of influence on local policies. Further, positions of Aldermen provide local politicians with prestige and, mainly in larger municipalities, well-paid jobs.

To test the hypotheses derived in the preceding section, three assumptions have to be introduced regarding (1) the measurement of political support, (2) the position of the appointed Mayor, and (3) the policy positions of the various local parties.

\subsection{Support of coalitions}

Only political parties represented in the Council of Mayor and Aldermen are assumed to support the governing coalition. This assumption may be problematic for the smallest municipalities. In those cases only two positions as Alderman are available, as determined by law. Because of the rather limited number of seats, it is possible that not all supporting political parties are represented in the executive committee. Consequently, the inclusion of these municipalities will lead to a biased test in favor of size oriented models and especially the minimum number principle. Because of this problem the proposed hypotheses will be tested for different groups of municipalities depending on the available number of positions of Aldermen. 


\subsection{The Mayor}

Although the Mayor is an appointed member of the Council of Mayor and Aldermen, he also is a member of one of the national political parties. Therefore, it is conceivable that political parties take the Mayor's party affiliation into account when they distribute the available positions of Aldermen. For this reason two variants will be distinguished in Section 5: The first variant bases the governing coalition on the party membership of Aldermen alone; the second variant uses the party membership of the Aldermen as well as the Mayor to determine the parties represented in the coalition.

\subsection{Policy positions of local parties}

Another question to be dealt with concerns the ideological positions of local political parties. As indicated earlier, empirical research on the policy positions of these parties is absent. Therefore, we construct a policy ordering of parties.

With respect to national parties it is likely that their local policy positions do not much differ from their positions at national level. As indicated in the introduction, local government in the Netherlands is more or less dependent on the central government. This dependency suggest that differences in policies between the two levels of government should be very limited. ${ }^{13}$ Further, this situation also implies that the same policy dimensions may be involved in local as well as in national politics.

Given identical policy dimensions, there are at least two reasons to expect that local branches of national parties do not deviate from policy positions of their national counterparts. First, within a municipality both the local branch and the national party share the same electorate. If voters notice different policy positions, or 'inconsistencies', a party may lose the confidence of voters, leading to a loss of electoral support. Therefore, the national party and the local branches have a strong incentive to maintain identical policy positions. Second, another incentive arises if careers of local politicians are considered. These politicians may aim at positions in the national party apparatus, or at political positions at central government level or the level of provinces. A deviation from the national party-line will decrease the candidate's support within the party, reducing his chances of being promoted. This mechanism also leads to more or less identical policy positions for different local branches of the same national party. Summarizing this argument, it is expected that:

(1) the policy dimensions on which parties can be ordered are the same for local and central government, and

(2) the ordering of local parties on this scale is identical between municipal- 
ities,${ }^{14}$ and can be derived from the ordering of political parties at the national level. ${ }^{15}$

Using these expectations as assumptions, local branches of national parties can be ordered in the national policy space.

The ordering of national political parties in the Netherlands using elections manifestos is analyzed in several studies (see for example Lipschits, 1969: 104-16; Dittrich, 1987). In most studies it appeared that politics in the Netherlands is dominated by one dimension interpreted in terms of social economic problems. Dittrich, who recently analyzed the content of election manifestos with factor analysis, interpreted the most important factor as the 'traditional' social economic dimension (1987: 223). Using Dittrich's results the following ordering of national political parties is proposed. ${ }^{16}$

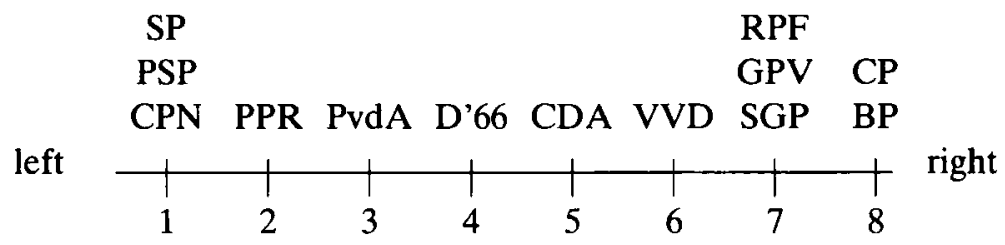

The ordering of extreme parties differs sometimes in empirical research. For this reason the same policy positions are assumed for PSP and CPN, for SGP, GPV and RPF, and for CP and BP. ${ }^{17}$

Concerning the elections of 1982 the ordering of parties on Dittrich's most important factor changed with respect to D'66. This party is found on the left side of PvdA instead of the right side. This effect can be caused by issues related to democracy, ${ }^{18}$ which are strongly emphasized by D' 66 and positively related with the 'social economic' factor in Dittrich's study. ${ }^{19}$ Because of this empirical problem, an alternative ordering of parties will be used as well, which takes into account the ambiguous position of D'66. This alternative is:

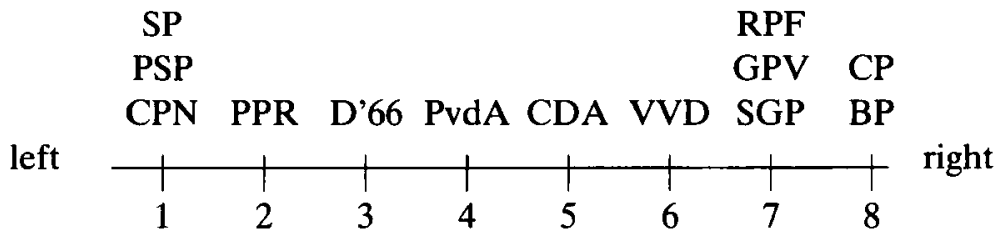

Thus, orderings [1] and [2] will be considered as different variants of a policy ordering of political parties. These orderings are alternative specifications and not dimensions of the same policy space.

The positions of combinations of national lists, and in some cases also combinations of national and local lists, are not known yet. These combina- 
tions are imputed to the largest party viewed from a national perspective. Combinations of GPV and/or SGP and/or RPF are labelled PCG ('Protestant Christian Groups'), and these combinations are attributed to the position of these parties. Further, the already mentioned PAK-lists are distinguished into: (1) PAK-1, they are combinations of CPN, PSP, PPR and/or D'66 with PvdA; these combinations are attributed to the policy position of PvdA, (2) PAK-2 or combinations without PvdA, but with D'66; these lists are imputed to the position of D'66, and (3) PAK-3 or combinations of PPR, PSP and/or CPN, which are attributed to the position of PPR. For example, ordering [1] can be extended as follows:

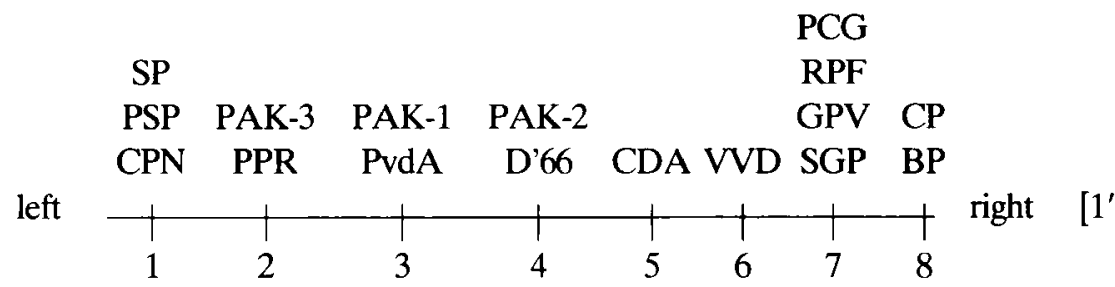

Information on policy positions of local lists is not available. In the south of the Netherlands local lists are often classified as Roman Catholic lists, but this label does not imply that these groupings share equal positions (see, for instance, Dittrich, 1983). Moreover, it is questionable whether the positions of Roman Catholic lists coincide with the policy position of the christian democratic CDA as Denters (1985: 301) assumed. Because of their unknown policy positions municipalities with local lists should be excluded when the policy oriented models and the central player principle are tested. This principle would lead to the exclusion of a large number of cases, even when local lists occupy a relatively small number of seats in the municipal council, which points to a trade-off between reliability and the number of cases for which coalition theories are tested. The larger the number of municipalities with a relatively high proportion of local lists that is included in the analysis, the higher the degree of information owing to a larger number of cases, but the lower the reliability of the analysis because of the unknown policy positions of these lists. This trade-off is visualized in Figure 1. The vertical axis gives the cumulative, relative number of municipalities ordered to the proportion of seats of local lists, while the proportion of seats of local lists is depicted on the horizontal axis.

In a substantial number of municipalities the relative number of seats of local lists is small. Given the trade-off between information and reliability a point is sought for which an increase of the proportion of local lists does not lead to a substantial increase of the number of cases. Such a point is found at 


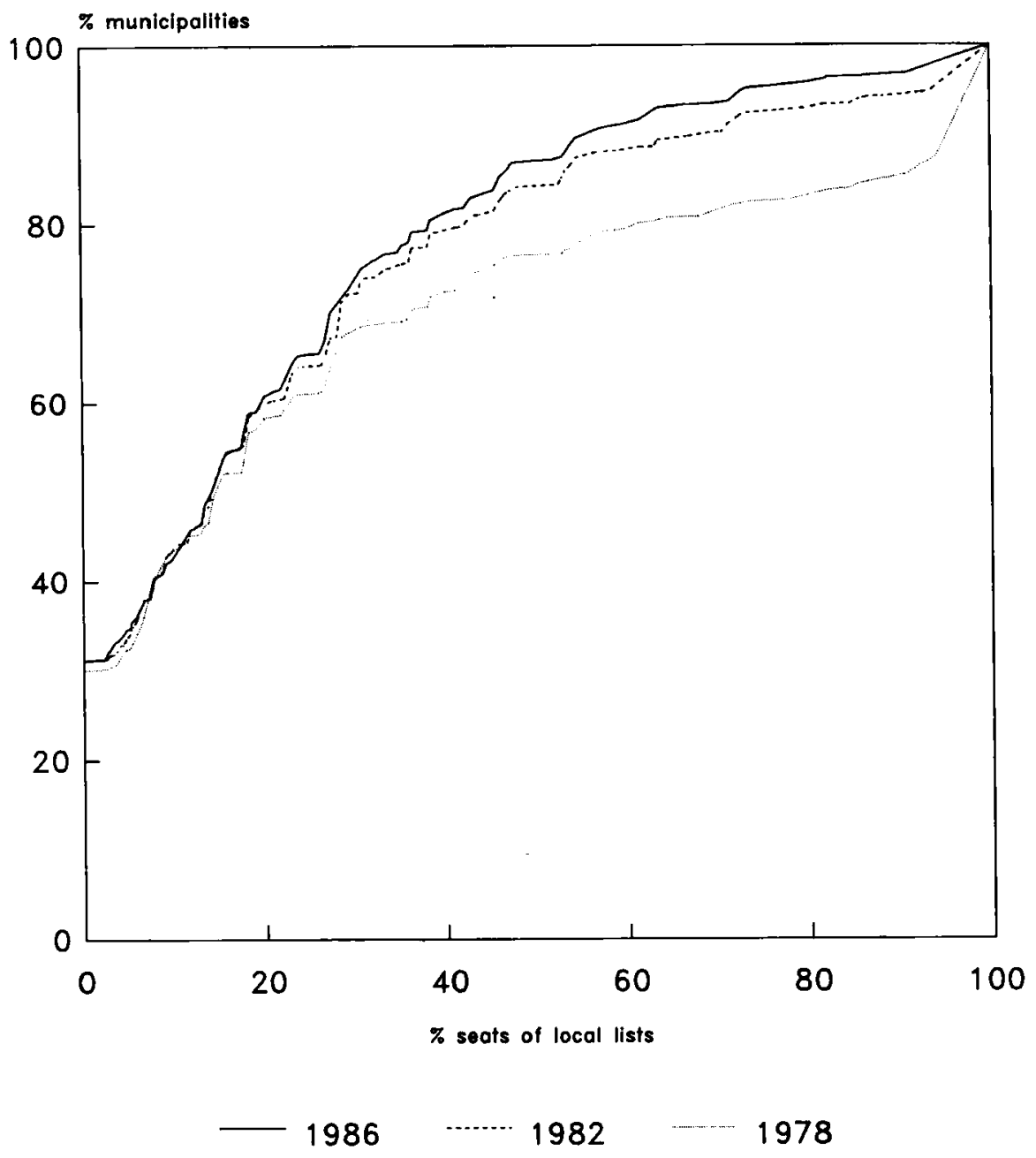

Fig. 1. Shares of seats of local lists in municipal councils and the cumulative number of municipalities, which are ordered to their share of local lists (in percentages).

$20 \%$ of the seats in Figure $1 .^{20}$ Therefore, we omit local lists in the analysis if they occupy $20 \%$ or less of the seats in the municipal council. Municipalities are excluded from our analysis if local lists have more than $20 \%$ of the seats at their disposal in the municipal council. Furthermore, if a local list is represented in the Council of Mayor and Aldermen the municipality is excluded as well. ${ }^{21}$ 


\section{Statistical tests for the predictive power of coalition theories}

The results of empirical analyses of coalition formation are often presented as the number of correct predictions (see for example Peleg, 1981; Roozendaal, 1989; Van Deemen, 1990) or 'success rates'. ${ }^{22}$ Such a presentation has several limitations. First, the number of predicted coalitions are often larger than one, while 'success rates' do not account for the number of coalitions in the prediction set. In that case the most successful theory would be the 'naive' theory predicting all possible coalitions. In other words, the prediction of the correct coalition is not a sufficient condition to judge the empirical validity of a theory. A neccessary condition is precision, which ideally implies that the prediction set should only contain the coalition that is actually formed. Second, and in connection with the preceding point, using 'success rates' it is not clear whether the prediction made by theory is better than a random choice between all possible coalitions.

Several test statistics have been suggested to determine the predictive power of coalition theories. These tests depart from the notion that the number of successful predictions should be higher than a random selection of coalitions from the set of all possible coalitions. Mokken (see De Swaan, 1973: 304-7) suggested determining the probability of a correct prediction for each interelection period. According to his assumptions this probability can be described with a hypergeometric distribution. Further, the results of these tests for the $k$ inter-election periods are combined in an overall statistic originally proposed by Fisher. This overall statistic follows a chi-square distribution with $2 k$ degrees of freedom.

Taylor and Laver (1973: 217-21) modified Mokken's test statistic in several aspects. Mokken restricted the set of possible coalitions to winning coalitions for computing probabilities, while Taylor and Laver also included all losing coalitions. Mokken assumed that coalitions are drawn randomly without replacement, while Taylor and Laver suggested a random sample with replacement. In that case the probability of being selected follows the binomial distribution. Laver and Taylor corrected the overall test statistics for discontinuity. However, even if a correction for discontinuity is used, it is doubtful whether the suggested overall statistic follows a chi-square distribution (see Kincaid, 1962) because of the very limited number of values for the binomial variable (in this paper the number of successes only has two values, that is: 0 or 1).

An alternative to the test statistics of Taylor, Laver and Mokken is suggested by Gamson (1962: 166-7) and, recently, independently of Gamson reported by Boute (1988: 155-9). They consider the number of successes for the various coalition formations within the $k$ inter-election periods as drawn from the same population. If the number of cases is relatively large, the central-limit 
theorem can be used to determine the probability distribution. This solution is also followed in this paper.

Let $n$ be the number of cases, or municipalities, and $r_{i}, i \in\{1,2,3 \ldots n\}$, the number of coalitions in the prediction set for case $i$. The number of winning coalitions for the same case is denoted as $t_{i}$. The probability of a correct prediction for case $i$ is:

$$
\mathrm{p}_{\mathrm{i}}=\mathrm{r}_{\mathrm{i}} / \mathrm{t}_{\mathrm{i}}
$$

Subsequently, the number of correct predictions for municipality $i$ will be denoted as $s_{i}$, which has only two values (one if the prediction is correct, or nil if the prediction is not correct).

The number of possible coalitions is limited to winning coalitions. Taylor and Laver, however, also included losing coalitions to this set. This approach is not followed for several reasons. First, most models considered in Section 2 are based on simple game theory assuming that the complement of a winning coalition is a losing one. In those cases it is not appropriate to test the proposed hypotheses for the formation of minority governments for which the complement of a winning coalition can be a winning coalition. Second, Taylor and Laver motivated their choice by pointing out that they also considered the set of winning coalitions as a 'hypothesis'. But, in this way they confuse a criterion used in simple game theory with theoretical hypotheses proposed in several models within that approach. Furthermore, enlargement of the set of possible coalitions may lead to an overestimation of the predictive power of coalition theories.

Given the probability of selecting a correct coalition the following nullhypothesis will be tested for each theory:

$$
\mathrm{H}_{0}: \sum \mathrm{p}_{\mathrm{i}} \geqslant \sum \mathrm{s}_{\mathrm{i}}
$$

with $p_{i}$ and $s_{i}$ summed over all cases $i \in\{1,2,3 \ldots n\}$. The alternative hypothesis is:

$$
\mathrm{H}_{\mathrm{i}}: \sum \mathrm{s}_{\mathrm{i}}>\sum \mathrm{p}_{\mathrm{i}},
$$

which indicates that the prediction of a specific theory is better than a random selection of a coalition.

Using the central-limit theorem it is generally known that, when the number of cases becomes large ${ }^{23}$ the binomial distribution may be approximated by the normal distribution with an expected number of successes equal to $\sum p_{i}$ and variance equal to $\sum p_{i}\left(1-p_{i}\right)$. The condition of a large number of cases is sufficiently fulfilled in the empirical analysis, which mostly uses approximately 
a hundred cases or more. The hypotheses derived in Section 2 will be tested for the (relevant) population of Dutch municipalities. The test statistic $Z$, which uses population parameters, can be computed as follows ${ }^{24}$ (see Gamson, 1962: 167):

$$
\mathrm{Z}=\frac{\sum \mathrm{s}_{\mathrm{i}}-\sum \mathrm{p}_{\mathrm{i}}}{\sqrt{\sum \mathrm{p}_{\mathrm{i}}\left(1-\mathrm{p}_{\mathrm{i}}\right)}}
$$

The higher this $Z$-value, the smaller the probability that a theory gives a false prediction. For $\mathrm{Z}$ a level of significance can be obtained from the normal table.

The hypotheses are tested using a $1 \%$-level of significance and a one-tailed test. ${ }^{25}$ Moreover, the Z-values of different hypotheses follow the same distribution, and, therefore, they can be easily compared. The higher the Z-value of a significant hypothesis, the better the prediction of this theory compared with other theories.

\section{Empirical analysis}

We now confront the hypotheses formulated in Section 2 with data from Dutch municipalities. Not all municipalities will be examined. In some municipalities one political party has a majority of seats in the municipal council. In that case the outcome of the formation process cannot be predicted significantly by coalition theories, because the result is solely determined by this actor. Municipalities with such a 'dictator' are excluded from our analysis. This concerns 284 cases in $1978(34 \%), 105$ in $1982(14 \%)$, and 94 in $1986(13 \%)$.

\subsection{Size oriented models and the dominant player principle}

Size oriented models and the dominant player principle can be tested for the municipalities without a dictator ${ }^{26}$ The empirical results are presented in Table 1. Columns 1 to 8 provide results for coalition formations after the 1986 elections. For columns 1 to 7 , the identity of the represented political parties has been exclusively determined by the party membership of Aldermen.

The first column gives the success rates for the various models. The weak domination version of the dominant player principle (Hypothesis 9) appears to have the highest success rate, that is $82 \%$. However, as stated in Section 4 , this percentage does not provide a valid insight into the predictive power of a theory. This becomes clear if the success rate is compared with the Z-value, and when one takes notice of the expected number of correct predictions $\left(\sum \mathrm{p}_{\mathrm{i}}\right)$, which is stated in the third column, in comparison with the absolute 
number of correct predictions $\left(\sum \mathrm{s}_{\mathrm{i}}\right)$ given in the second column. The principle turns out to have a relatively high number of correct predictions (285), which determines the large value of the success rate, but also a high expected number of correct predictions (233). This leads to a relatively small Z-value (column 4). Although this $Z$-score is still significant, other models with smaller success rates provide better predictions (see, for instance, the minimum number principle).

The null-hypothesis, meaning that the expected number of correct predictions is larger or equal to the number of correct predictions, has to be rejected for most hypotheses. An exception is the minimum size principle, which does not have a significant result. An objection, however, is that the limited number of Aldermen in small municipalities may have distorted these results. Therefore, columns 5, 6 and 7 of Table 1 present results reported for municipalities with two, three and four or more Aldermen. As expected, the size oriented models seem to predict better in the group with two Aldermen, but this result is merely caused by the limited number of available positions. This becomes clear if these Z-values are compared with the values found for the other two groups. In all cases those values are lower or are not significant.

As indicated in column 7 of Table 1 the minimum size principle and its combinations with the dominant player principle have to be rejected as predictive principles. Also the weak domination version of the dominant player principle does not provide a significant explanation. Moreover, as expected, this version is less significant than the strong version of the dominant player principle, which does give significant results.

Especially the minimum number principle and its combinations with the dominant player principle are highly significant. The relatively precise predictions of this actor-oriented model, together with its combinations with some of the behavioral models, are in line with the expectation that the bargaining position of political parties is important for formation processes in local government in the Netherlands. Moreover, as expected, combinations of the dominant player principle and size oriented models hold higher Z-values than those models separately.

In column 8, results are presented for the set-up that uses the party membership of Aldermen as well as the Mayor to determine the participating parties in the coalition that is formed. The results for this variant appear to be less significant than for the computations based on Aldermen alone (see column 7). This indicates that, in most municipalities, political parties most likely do not reckon with the political affiliation of the Mayor when calculating the representation of parties in the governing coalition. The same can be concluded for the municipalities with two or three Aldermen. The statistics for these cases are not presented here.

Finally, columns 9 and 10 of Table 1 present results for coalition formations 


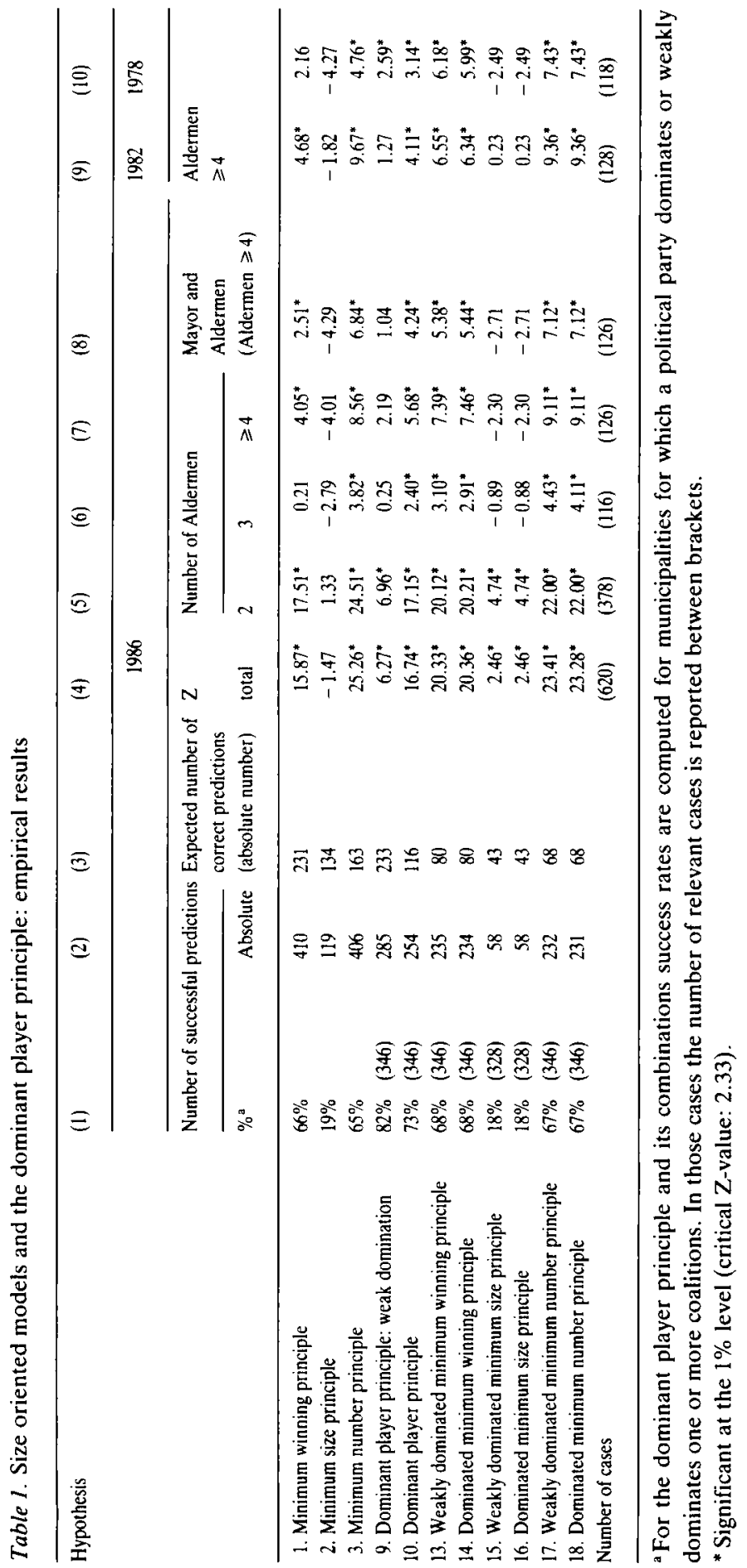


after the elections in 1978 and 1982 . These results can be compared with the results for the 1986 elections presented in column 7 . From these columns some interesting changes can be noticed. First, the minimum winning principle gives significant predictions for the outcome of the formation processes after the elections in 1982 and 1986, while this principle does not hold significant results for 1978. In the case of the minimum number principle a similar tendency is noticed in the sense that the significant Z-values for 1982 and 1986 are much higher than for 1978. Second, predictions of the dominant player principle (Hypothesis 10) turn out to be significant for all studied elections. Combined with the minimum winning and the minimum number principle these predictions are even better. Again, the highest Z-values, and, thus, the best predictions, are found for the dominated minimum number principle.

\subsection{Policy oriented models and the central player principle}

In order to test the policy oriented models and the central player principle municipalities are excluded that have local lists represented in the municipal council for more than $20 \%$ of the seats. Moreover, if a local list is represented in the Council of Mayor and Aldermen the municipality is also excluded.

The empirical results are presented in Table 2. Columns 1 to 5 give the results for the 1986 elections. D'66 is now ordered to the right of PvdA (ordering 1) as well as in columns 6 and 7 . Further, in columns 1 to 4 coalition members are determined by the political membership of Aldermen alone.

Results are provided for three subsets of municipalities. As in the case of size oriented models and the dominant player principle, the limited number of Aldermen in small municipalities distorts the empirical results especially in favour of the minimum diversity principle, the minimum range principle and the dominant central player principle. Therefore, the attention in this section is also focused on municipalities with four or more Aldermen.

From column 4 in Table 2 it appears that for 1986 the minimum diversity principle, the subjective policy distance principle, the central player principle and the dominant central player principle have to be rejected as predictive theories. None of these models gives a significant result. The other models have significant $\mathrm{Z}$-values, but these values are rather low compared with results found in Section 5.1.

The results based on Aldermen alone can be compared with the variant for which coalitions are also determined by the political affiliation of the Mayor (see column 5). For this variant most $Z$-values turn out to be smaller, which confirms our earlier conclusion that political parties probably do not reckon with the Mayor's party membership.

Columns 6 and 7 of Table 2 present results for coalition formations after the 


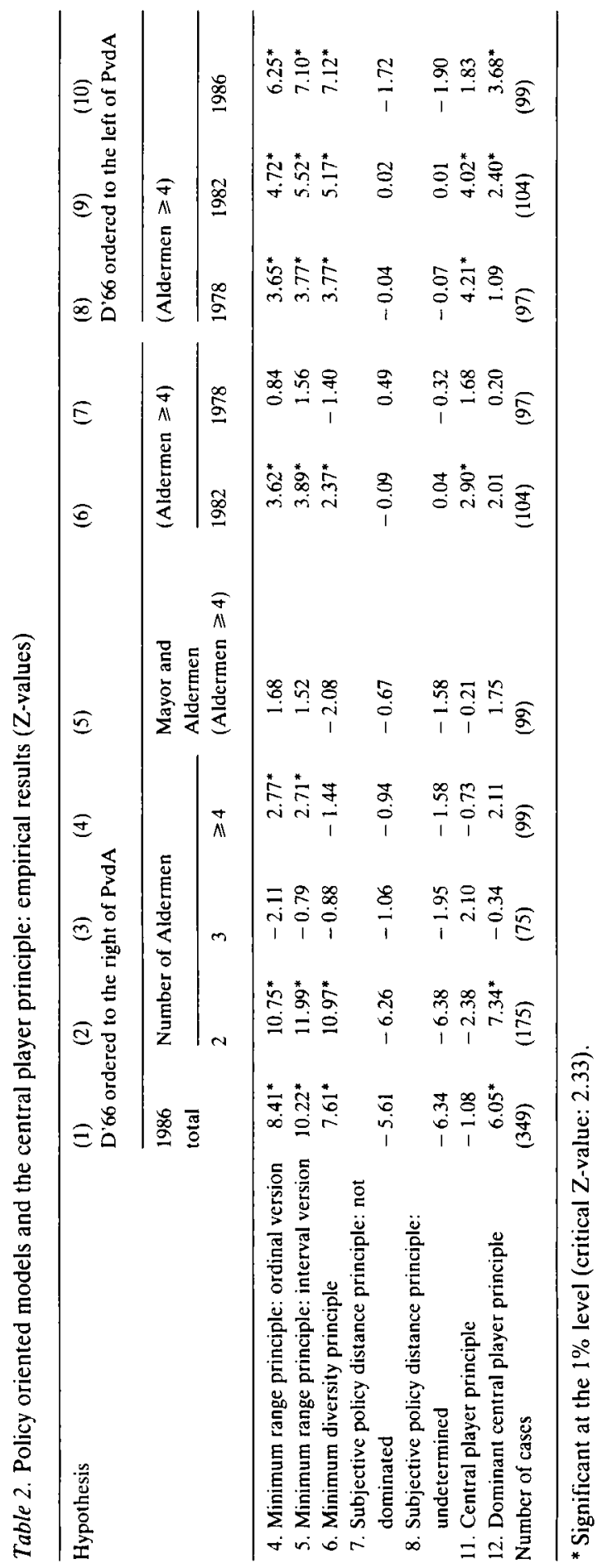


elections in 1978 and 1982. These results can be compared with the results for the 1986 elections given in column 4 . It turns out that most principles, if they have significant results for 1982 or 1986, do not hold significant predictions for 1978. The central player principle, however, has a significant Z-values for 1982, but for 1986 and 1978 the predictions of this principle are not significant.

One reason for this instability of the results, and more generally the disappointing results of the policy oriented models, is perhaps the ordering of political parties. If this ordering is false, these models may not predict the formed coalition correctly. An alternative ordering of political parties is proposed in Section 3.3 with respect to D'66. Instead of a policy position between PvdA and CDA, D'66 is ordered to the left of PvdA (ordering 2). The results of this analysis, presented in column 8,9 and 10 of Table 2 , are striking. The minimum range principle and the minimum diversity principle have very significant results, also for 1978. So, from an empirical point of view D'66 is likely to be found at the left side of PvdA (ordering 2) and not at its right side (ordering 1). An exception is the policy distance theory, which still is insignificant.

The relatively precise predictions of some of the policy oriented models were not expected. Policy considerations appear to play a more important role in local coalition formation. Also note that the change of the position of D'66 especially affects models that stress the ideological cohesiveness of coalitions.

\subsection{Comparison}

The best size oriented models, policy oriented models and actor oriented models are confronted with each other in Table 3 . The results presented in this table are computed for the same population, ordering D'66 to the left of PvdA (ordering 2). Models not included in the table do not yield significant predictions for two or more election periods. These models, such as the minimum size principle and the subjective policy distance theory, are rejected as predictive theories in the case of Dutch municipalities.

The most successful models are the size-oriented and dominant player approaches, and their derivatives. An exception is, of course, the (rejected) minimum size principle. This result is remarkable for several reasons. First, Denters (1985: 302) concluded that none of the models he tested yields significant predictions. Clearly, this result is mainly due to the incorrect test statistic that was used. Some of the models rejected by Denters do give significant results. Second, size oriented models predict governing coalitions nearly as precisely as some of the policy oriented models. Thus, Franklin and Mackie's (1984: 686) observation that policy considerations dominate Dutch national cabinet formation is not confirmed for the local level. Also non-policy 
benefits of coalition formation appear to matter in local government. This result provides some support for our expectation that different models may perform better depending on the institutional setting.

The more recent models, such as the dominant player principle and the central player principle, have varying results. The weak domination version of the dominant player principle is rejected as a predictive theory. The central player principle and the dominant player principle ${ }^{27}$ have significant results and, especially, combinations of the dominant player principle with some of the size oriented models provide rather precise predictions. The dominant minimum size principle, recently suggested by Van Deemen (1989: 325-8), showed to be a poor predictor and is, therefore, rejected.

The hypothesis with the highest Z-values for 1978 as well as for 1982 is the dominated minimum number principle. This success provides evidence in favour of our expectation that preferences and bargaining power matter in formation processes at the local level in the Netherlands. Some of the policy oriented models also provide significant results, but in general these models are less precise.

Finally, two comments can be made regarding the empirical performance of the models. First, as Table 3 showed, the relative number of correct predictions

Table 3. Predicted coalitions measured by the party membership of Aldermen for municipalities with four or more Aldermen: comparison of significant models for the same population. D'66 ordered to the left of PvdA (success rates between brackets)

\begin{tabular}{|c|c|c|c|}
\hline Hypothesis & 1978 & 1982 & 1986 \\
\hline 1. Minimum winning principle & $0.94(35 \%)$ & $3.14^{*}(36 \%)$ & $3.80 *(43 \%)$ \\
\hline 3. Minimum number principle & $2.22(33 \%)$ & $5.59^{*}(32 \%)$ & $6.53^{*}(42 \%)$ \\
\hline 4. Minimum range principle: ordinal version & $3.65^{*}(31 \%)$ & $4.72 *(25 \%)$ & $6.25^{*}(36 \%)$ \\
\hline 5. Minimum range principle: interval version & $3.77^{*}(30 \%)$ & $5.52 *(24 \%)$ & $7.10^{*}(34 \%)$ \\
\hline 6. Minimum diversity principle & $3.77^{*}(30 \%)$ & $5.17^{*}(23 \%)$ & $7.12 *(34 \%)$ \\
\hline 10. Dominant player principle ${ }^{a}$ & $1.31(51 \%)$ & $2.28(47 \%)$ & $4.27^{*}(64 \%)$ \\
\hline 11. Central player principle ${ }^{a}$ & $4.21 *(99 \%)$ & $4.02 *(96 \%)$ & $1.83(90 \%)$ \\
\hline 12. Dominant central player principle ${ }^{a}$ & $1.09(52 \%)$ & $2.40^{*}(57 \%)$ & $3.68 *(69 \%)$ \\
\hline \multicolumn{4}{|l|}{ 13. Weakly dominated minimum winning } \\
\hline principle $^{\mathbf{a}}$ & $4.38^{*}(43 \%)$ & $4.64 *(36 \%)$ & $5.72^{*}(46 \%)$ \\
\hline 14. Dominated minimum winning principle ${ }^{a}$ & $4.16 *(41 \%)$ & $4.36^{*}(34 \%)$ & $5.72 *(46 \%)$ \\
\hline \multicolumn{4}{|l|}{ 17. Weakly dominated minimum number } \\
\hline principle $^{a}$ & $4.70 *(40 \%)$ & $5.91^{*}(34 \%)$ & $6.65^{*}(45 \%)$ \\
\hline 18. Dominated minimum number principle ${ }^{a}$ & $4.70 *(40 \%)$ & $5.91^{*}(34 \%)$ & $6.65^{*}(45 \%)$ \\
\hline Number of cases & $(97)$ & $(104)$ & (99) \\
\hline
\end{tabular}

${ }^{a}$ For the central player principle, the dominant player principle and their combinations success rates are computed for municipalities for which a political party is central to the policy ordering or it dominates or weakly dominates one or more coalitions.

* Significant at the $1 \%$ level (critical Z-value: 2.33 ). 
of the dominated minimum number principle is rather limited. The values vary between $34 \%$ for 1982 and $45 \%$ for 1986 . Other principles, such as the central player principle, have much higher success rates, but these models are less precise in their predictions as the lower Z-values indicate. Second, the predictions of coalition theories can be compared with a 'prediction' based on the status quo, that is the composition of the Council of Mayor and Aldermen in the 'preceding' period. Using the coalitions formed after the 1982 elections as predictors for the coalition formations in 1986, this simple 'rule of thumb' has a significant Z-value of 16.41 and a success rate of $48 \%$. This result is far more precise than the dominant minimum number principle and any other tested coalition model. Thus, although the predictions of most coalition models proved to be statistically significant, their performance is still rather poor.

\section{Conclusions}

The paper analyzes coalition formation in Dutch local governments in which political parties represented in the municipal council have to form a municipal executive committee from among their members. Contrary to national cabinet formations in the Netherlands, no 'formateur' is appointed, and political parties directly bargain to be included in the local coalition, that is, the Council of Mayor and Aldermen. The empirical analysis leads to the following conclusions:

(1) The formation process in Dutch municipalities can be typified as an 'unrestricted' formation process. All represented political parties are allowed to propose some coalition, and none is formally excluded from this process. Therefore, models which emphasize the strategic position of a player are expected to perform better in this context than other models. This implication is only partly confirmed. The dominant player principle, as well as the central player principle, provide significant predictions for most formation processes, but some of the size or policy oriented models are at least as significant (for example, the minimum number principle or the minimum range principle). Also preferences appear to be important in addition to bargaining strength. Moreover, the weak domination version of the dominant player principle is mainly insignificant and is rejected as a predictive theory.

The insignificance of the weak domination version can be the result of its limited concept of power. Contrary to the stronger version, the only requirement of this principle is that the dominant player also can form a winning coalition with parties with which the internal opposition can win. So, if the internal opposition tries to form a coalition with some party, the dominant player can also make him an offer. If the dominant player is not able to form a winning coalition with some party, the internal opposition cannot too, if their 
coalition is weakly dominated. Thus, in case of weak domination the dominant player and the internal opposition have the same opportunities to form a coalition with other players. The stronger version provides the dominant player much more bargaining strength. Then, he also can form a winning coalition with parties with which the internal opposition cannot win.

(2) As well as their strategic position, the preferences of political parties may be important for coalition formation. Motivations stressed by the more traditional size and policy oriented models are expected to be useful in combination with actor oriented models, as when the dominant player principle is combined with the minimum winning principle and its extensions. The central player principle, which already emphasizes policy preferences and strategic considerations, is combined with the dominant player principle. Do these 'mixed' theories provide better predictions?

The dominated minimum number principle provides very significant results and some evidence in favour of our expectation. The same holds for the dominated minimum winning principle. The dominated minimum size principle, however, performs rather poorly. The insignificant results of this principle seem to be due to a more general failure of the minimum size principle to explain coalition formation at the municipal level. With respect to policy preferences, the minimum range principle and the minimum diversity principle yield better results than the central player principle and the dominated central player principle. So, the expected performance of 'mixed' models is only confirmed for size oriented models.

(3) Size considerations are expected to be more appropriate than policy considerations in the context of Dutch local government. The main reason is the dependence of local governments on the central government leading to a mainly 'national' orientation of voters at local elections. As expected, some of the policy oriented models appear to predict coalition formation rather poorly, especially the subjective policy distance theory, which is rejected. Contrary to our expectation, however, the minimum range principle and the minimum diversity principle provide rather precise predictions.

A possible explanation for this result is the fact that, in the Netherlands, the three largest parties are located in the centre of the distribution of voter preferences. Winning coalitions of CDA and PvdA, or CDA and VVD do not contain an unnecessary player and have the smallest number of parties. Moreover, these coalitions are of minimum range or diversity if D'66 is ordered to the left of PvdA (see ordering 2). ${ }^{28}$ Thus, the presence of these large centre parties in most municipal councils is compatible with both size and policy oriented approaches to coalition formation. If, however, the policy position of D'66 is located to the right of PvdA (ordering 1), a coalition of CDA and PvdA may not be ideologically cohesive anymore. Now, the results 
of the minimum range and the minimum diversity principles are less significant or even insignificant, given the presence of D'66 in many municipal councils.

(4) The empirical results are computed for several types of situation. First, as expected, the results appear to be distorted in the smallest municipalities, with only two Aldermen. Although most size oriented models predict well for these cases, the highly significant results disappear in larger municipalities with more Aldermen. Therefore, in the remaining part of the paper our attention has been focused on the municipalities with four or more Aldermen. Second, if the political affiliation of the Mayor is taken into account, the empirical results turn out to be less significant. This effect indicates that in most municipalities political parties probably do not reckon with the Mayor's party membership in forming a coalition. This result may have been caused by the more or less independent position of the Mayor in the Netherlands and the incapacity of local councils to discharge the Mayor formally. Third, for D'66 two different policy orderings are tested. If D'66 is ordered to the left of PvdA all policy oriented models provide more significant predictions.

The analysis in this paper gives rise to several questions, which can be regarded as topics for further research:

(1) In this paper the ordering of local political parties is derived from an ordering of national parties. It is, however, not clear whether this ordering is accurate. Further, because of their unknown policy positions, local lists are neglected in the analysis. In order to extend the analysis to a larger number of cases with regard to policy oriented models, it is necessary to pay attention to the positions of these parties. An analysis of local party manifestos can throw light on both matters. In addition, a one-dimensional policy ordering is assumed, though this assumption also needs to be further investigated. If more than one dimension is important in the case of local politics, and if local parties are ordered differently from one municipality to another, then the policy oriented models may hold different and perhaps more significant results.

(2) The dominant minimum number principle appears to provide the best predictions, though this does not imply that other models are not worth considering. It would be interesting to explore the dominant minimum number principle in combination with, for instance, policy oriented models. Furthermore, the structure of the formation processes at the national as well as the local level of government needs to be modelled more explicitly. As indicated, the institutional arrangements of national or local politics may affect coalition formation differently. Not all political parties may have access to the 'arena of coalition formation', and some player may have a special position, as is the case at the national level in the Netherlands. The empirical analysis in this 
paper provides some evidence in favour of an institutional approach, but much work still has to be done.

\section{Acknowledgements}

Thanks are due to Ad van Deemen, Bas Denters, Jan van Deth, Peter Geurts and two anonymous referees for their comments. I am indebted to Frederike Gossink, Rita van der Meulen, Edwin de Vries and Hans Zandberg for their research assistance. An earlier version of this paper was presented at the Meeting of the European Public Choice Society in Meersburg, Germany, April 18-21, 1990.

\section{Notes}

1. Denters used a test statistic that resembles the one Taylor \& Laver have suggested without the correction for discontinuity. As in Section 4 will be noticed this statistic only gives a very rough or even incorrect approach of significance.

2. Various aspects of the Dutch political system are dealt with in a special issue of West European Politics: Politics in the Netherlands: How Much Change? (1989, 12: 1-185). This issue also contains an extensive bibliography of publications on Dutch politics written in English.

3. See for a more extensive survey on the position of the Mayor in the Dutch local political system and his appointment by the central government: Andeweg \& Derksen (1978).

4. In the empirical part of this paper hypotheses are conceived as attempts to predict correctly as many coalitions as possible. Although all formed coalitions should be predicted correctly from a strictly deterministic point of view, each theory is probably not complete, leading to deviations from the formulated principle.

5. Although Riker is mentioned as one of the proposers of this hypothesis, his argument does not imply a minimum size principle as De Swaan (1973: 52-62) noted. What is missing is an assumption about the distribution of benefits in Riker's theory. So this theory predicts minimum winning coalitions instead of minimum size coalitions.

6. For multi-dimensional models and the problem of an empty core, see Schofield, Grofman \& Feld (1988).

7. If the weights of parties $i$ and $j, i, j \in N$, are not equal, $w(i) \neq w(j)$, a simple game is called a weighted majority game.

8. See Peleg (1981: 17-8). This condition is not investigated following the interpretation of the dominant player used by Van Deemen.

9. A proof of this principle is comparable to Van Deemen's proof of the dominated minimum size principle.

10. The maximum number of represented political parties is 10 . The minimum of two parties is found in only $0.6 \%$ of the municipalities.

11. Other national parties that are represented in municipalities are Democrats 1966 (D'66), Radical Party (PPR), Pacifist Party (PSP), Communist Party of the Netherlands (CPN), Socialist Party (SP), conservative christian parties such as GPV, SGP and RPF, and the extremist Center Party (CP) and Farmers Party (BP). 
12. The Netherlands Bureau of Statistics classifies these lists as Independents, Roman Catholic Lists and local Protestant Christian Lists.

13. Exceptions are, of course, foreign and European policies, stabilization or macroeconomic policies of the central government, and, to some extent, policies regarding the distribution of secondary income.

14. Only identical orderings are expected. Let $\mathrm{A}<\mathrm{B}<\mathrm{C}<\mathrm{D}$ be the ordering of the political parties A, B, C and D ('<' means 'more to the left than'). If, for instance, party B is not represented in a municipal council the following ordering with regard to the parties $A, C$ and $D$ is used: $A<C<D$. Using the minimum diversity principle the coalition $\{A, D\}$ has an ID $=3$ (two spaces, one hole) and not an ID $=5$. Further, the same coalition has a value of ' 2 ' and not of ' 3 ' if the interval version of the minimum range principle is used.

15. These expectations will be tested in a recently started research project on the dimensionality of Dutch local politics.

16. This ordering resembles in most cases orderings of political parties based on perceptions of voters (see Van der Eijk \& Niemöller, 1983: 249), perceptions of members of the Dutch House of Commons (see Daalder \& Van de Geer, 1977: 334-339) and 'expert' opinions (see Castles \& Mair, 1984: 80). See also the ordering proposed by De Swaan (1982: 224). A survey of older research on party positions is found in De Swaan's earlier study (1973: 242-5). The position of SP is determined using their party manifesto for the national election in 1981 (see Lipschits, 1981). Further, the numbers below the policy scale are used to determine the range of a coalition for the interval version of the minimum range theory.

17. After the 1978 elections CDA (a combination of KVP, CHU and ARP) as well as its joining parties KVP, CHU and ARP are represented in municipal councils. The 'Catholic People's Party' (KVP), the 'Christian Historical Union' (CHU) and the 'Anti-Revolutionary Party' (ARP), and various combinations of these parties, are attributed to the policy position of CDA.

18. It is questionable, however, whether democracy-related issues can be interpreted as elements of a 'social economic' dimension.

19. A similar problem occurs in Dittrich's study for the 'Democratic Socialists '70' (DS'70), which are not represented in municipal councils. Normally this party is ordered between CDA and VVD on the social economic dimension (see for example De Swaan, 1982: 224). Its position for the 1978 election is between D'66 and CDA according to the first factor, and the party is situated on the right side of VVD if the second and less important factor is used (interpreted as a modernization versus traditionalism dimension). This result also indicates that Dittrich's first factor can hardly be interpreted in social economic terms alone. Thus, it is not clear which 'dimension' is actually represented by this factor.

20. With regard to the trend, the first derivative changes from a positive value into a negative one for the first time at roughly $20 \%$. Beyond this point the marginal increase of the number of cases decreases if the relative number of seats of local lists is increased until these parties have a proportion of roughly $90 \%$.

21. The empirical results appear to be rather insensitive to these criteria.

22. Success rates are simply the number of correct predictions divided by the number of predicted cases.

23. Blalock adds to this proposition the following condition for the binomial distribution: $\sum \boldsymbol{p}_{i}>5$ where $\sum p_{i}<\sum\left(1-p_{i}\right)$ (see Blalock, 1972: 195-6).

24. Thus, the test statistic confronts population parameters and not population estimations based on a sample with the total number of correct predictions or successes.

25. A one-tailed test is chosen because we would like to know whether the correct number of predictions based on a specific theory is greater than expected.

26. In contrast to policy oriented models and the central player principle (see section 5.2) it is not 
necessary to exclude municipalities with a substantial proportion of local lists from the analyzed population. Data on the political representation in municipal councils as well as the representation of parties in the Council of Mayor and Aldermen are published by the Netherlands Bureau of Statistics (1978, 1982, 1986), the Union of Netherlands Municipalities $(1982,1986)$ and as 'Politiek Memo' by Kluwer $(1978,1983,1986)$. To determine the kind of a local party (national or local list), to trace the participating members of a combination of local branches of national parties, and to establish the number of seats of these parties these three sources are compared. If one of the publications shows a difference, an identical classification of the other two sources is adhered to. Should, nevertheless, a contradiction still exists, the municipality concerned is asked to supply additional information.

27. Note, however, that for the restricted population used in Table 3 the dominant player principle is not significant for 1982 and 1978. If all municipalities without dictatorial parties are used, the predictions of this principle are significant (see Table 1, columns 7, 9 and 10).

28. The less common coalition of PrdA and VVD is also a minimum winning and a minimum number coalition, but it does not fulfill the requirement of a minimum range or a minimum diversity coalition given the possibility of a coalition $\{C D A, P v d A\}$ or $\{C D A, V V D\}$.

\section{References}

Andeweg, R.B. and Derksen, W. (1978). The appointed burgomaster: Appointments and careers of burgomasters in the Netherlands, Netherlands' Journal of Sociology 14: 41-57.

Axelrod, R. (1970). Conflict of Interest: A Theory of Divergent Goals with Applications to Politics. Chicago: Markham Publishing Company.

Blalock, H.M. (1972). Social Statistics. Tokyo: McGraw-Hill.

Boute, S. (1981). On De Swaan's policy distance coalition theory, European Journal of Political Research 9: 313-320.

Boute, S. (1984). Subjective policy distance theory, pp. 113-126, in M.J. Holler (ed.), Coalitions and Collective Action. Wuerzburg/Vienna: Physica Verlag.

Boute, S. (1988). De vorming van coalities in de Belgische gemeenten, Tijdschrift voor Sociologie 9: $137-177$.

Browne, E.C. (1970). Testing theories of coalition formation in the European context, Comparative Political Studies 3: 391-412.

Browne, E.C. and Dreijmanis, J. (1982). Government Coalitions in Western Democracies. New York/London: Longman.

Browne, E.C., Gleiber, D.W. and Mashoba, C.S. (1984). Evaluating conflict of interest theory: Western European cabinet coalitions, 1945-80, British Journal of Political Science 14: 1-32.

Castles, F.G. and Mair, P. (1984). Left-right political scales: Some 'Expert' judgments, European Journal of Political Research 12: 73-88.

Daalder, H. and van de Geer, J.P. (1977). Partijafstanden in de Tweede Kamer der StatenGeneraal, Acta Politica 12: 289-345.

Deemen, A.M.A. van (1989). Dominant players and minimum size coalitions, European Journal of Political Research 17: 313-332.

Deemen, A.M.A. van (1990). Theory of center parties and cabinet formations: with an application to the Dutch parliamentary system, Acta Politica 25: 187-208.

Denters, B. (1985). Towards a conditional model of coalition behaviour, European Journal of Political Research 13: 295-309.

Denters, S.A.H. and Kerver, J.C.M. (1981). Politiek in gemeenten, pp. 335-366, in: R.B. 
Andeweg, A. Hoogerwerf and J.J.A. Thomassen (eds.), Politiek in Nederland. Alphen aan den Rijn: Samson Uitgeverij.

Dittrich, K.L.L.M. (1978). Partij-politieke verhoudingen in Nederlandse gemeenten: een analyse van de gemeenteraadsverkiezingen 1947-1974. Leyden: University of Leyden.

Dittrich, K. (1983). Limburg in de gemeentepolitiek: een analyse van de gemeenteraadsverkiezingen van 21 oktober 1981, pp. 45-61, in: F.H. van der Burg and M.A. van der Ham (eds.), Gemeentelijke vrijheden: opstellen aangeboden aan prof. $m r$. $M$. van Vliet bij haar afscheid als gewoon hoogleraar in het Staats- en Administratief Recht aan de Faculteit der Rechtsgeleerdheid van de Rijksuniversiteit Leiden op 1 september 1983. Alphen aan den Rijn: Samson Uitgeverij.

Dittrich, K. (1987). The Netherlands, 1946-1981, pp. 206-229, in: I. Budge, D. Robertson and D. Hearl (eds.), Ideology, Strategy and Party Change: Spatial Analyses of Post-War Elections Programmes in 19 Democracies. Cambridge: Cambridge University Press.

Eijk, C. van der and Niemöller, B. (1983). Electoral Change in The Netherlands: Empirical Results and Methods of Measurement. Amsterdam: CT-Press.

Einy, E. (1985). On connected coalitions in dominated simple games, International Journal of Game Theory 14: 103-125.

Franklin, M.N. and Mackie, T.T. (1984). Reassessing the importance of size and ideology for the formation of governing coalitions in parliamentary democracies, The American Journal of Political Science 28: 671-692.

Gamson, W.A. (1961). A theory of coalition formation, The American Sociological Review 26: 373-382.

Gamson, W.A. (1962). Coalition formation at Presidential nominating conventions, The American Journal of Sociology 68: 157-171.

Kincaid, W.M. (1962). The combination of tests based on discrete distributions, Journal of the American Statistical Association 57: 10-19.

Kuiper, W. and Tops, P. (1989). Local Coalition Formation in The Netherlands, pp. 220-239, in: Mellors and Pijnenburg (eds.).

Laver, M., Rallings, C. and Trasher, M. (1987). Coalition theory and local government coalition payoffs in Britain, British Journal of Political Science 17: 501-509.

Leiserson, M.A. (1966). Coalitions in Politics: A Theoretical and Empirical Study. New Haven: Yale University.

Leiserson, M.A. (1968). Factions and coalitions in one-party Japan: An interpretation based on the theory of games, The American Political Science Review 57: 770-787.

Lipschits, I. (1969). Links en rechts in de politiek. Meppel: Boom.

Lipschits, I. (1981). Verkiezingsprogramma's 1981. The Hague: Staatsuitgeverij.

Maas, P.F. (1982). Kabinetsformaties 1959-1973. The Hague: Staatsuitgeverij.

Mellors, C. and Pijnenburg, B. (eds.) (1989). Political Parties and Coalitions in European Local Government. London: Routledge.

Netherlands Bureau of Statistics (CBS) (1978). Statistiek der verkiezingen 1978: Gemeenteraden, 31 mei. The Hague: Staatsuitgeverij.

Netherlands Bureau of Statistics (CBS) (1982). Statistiek der verkiezingen 1982: Gemeenteraden, 2 juni. The Hague: Staatsuitgeverij.

Netherlands Bureau of Statistics (CBS) (1986). Statistiek der verkiezingen 1986: Gemeenteraden, 19 maart. The Hague: Staatsuitgeverij.

Neumann, J. von and Morgenstern, O. (1974) [1944]. Theory of Games and Economic Behavior. Princeton: Princeton University Press.

Peleg, B. (1981). Coalition formation in simple games with dominant players, International Journal of Game Theory 10: 11-33.

Politiek memo (1978). Editie provinciën en gemeenten. Deventer: Kluwer.

Politiek memo (1983). Editie provinciën en gemeenten. Deventer: Kluwer. 


\section{8}

Politiek memo (1986). Editie provinciën en gemeenten. Deventer: Kluwer.

Riker, W.H. (1975) [1962]. The Theory of Political Coalitions. New Haven/New York: Yale University Press.

Roozendaal, P. van (1989). Coalitietheorie en kabinetsformaties; een empirische confrontatie van drie nieuwe voorspellingsprincipes met data van kabinetsformaties in vijf Westeuropese landen (1945-1988), Mens en Maatschappij 64: 253-268.

Schofield, N. (1987). Stability of coalition governments in Western Europe: 1945-1986, European Journal of Political Economy 3: 555-591.

Schofield, N., Grofman B. and Feld, S.L. (1988). The core and the stability of group choice in spatial voting games, The American Political Science Review 82: 195-211.

Swaan, A. de (1973). Coalition Theories and Cabinet Formations; A Study of Formal Theories of Coalition Formation applied to nine European Parliaments after 1918. Amsterdam: Elsevier.

Swaan, A. de (1982). The Netherlands: Coalitions in a Segmented Polity, pp. 217-236, in: Browne and Dreijmanis (eds.).

Taylor, M. (1972). On the theory of government coalition formation, British Journal of Political Research 2: 361-386.

Taylor, M. and Laver, M. (1973). Government Coalitions in Western Europe, European Journal of Political Research 1: 205-248.

Union of Netherlands Municipalities (1982). Gids gemeentebesturen 82-86. The Hague: Union of Netherlands Municipalities Press.

Union of Netherlands Municipalities (1986). Gids gemeentebesturen 86-90. The Hague: Union of Netherlands Municipalities Press. 